\title{
锂硫二次电池正极研究进展
}

\author{
姚真东魏 巍王久林 ${ }^{*}$ 杨 军 努丽燕娜 \\ (上海交通大学化学化工学院, 上海 200240)
}

\begin{abstract}
摘要: 综述了锂硫电池中硫基正极材料的制备方法、结构特征以及电化学性能. 简述了单质硫正极材料, 重点 探讨了有机硫化物、碳/硫复合材料、聚合物/硫复合材料的结构设计、材料制备、反应机理以及充放电特性, 并对 其中存在的问题进行了分析, 还介绍了硫化锂正极材料. 最后对硫基正极的进一步发展, 以及锂硫电池的商业 化应用进行了展望.
\end{abstract}

关键词：锂硫二次电池； 正极； 硫基复合材料； 循环性能

中图分类号: $\mathrm{O} 646$

\section{Review of Sulfur-Based Cathodes for High Performance Lithium Rechargeable Batteries}

\author{
YAO Zhen-Dong WEI Wei WANG Jiu-Lin* YANG Jun NULI Yan-Na \\ (School of Chemistry and Chemical Engineering, Shanghai Jiao Tong University, Shanghai 200240, P. R. China)
}

\begin{abstract}
The preparation, characteristics and electrochemical performances of the sulfur-based cathode materials in lithium/sulfur batteries are reviewed in this paper. The elemental sulfur cathode material is briefly introduced. The structural designs, preparation processes, reaction mechanisms, and charge/discharge properties of organic sulfide, sulfur-porous carbon and sulfur-polymer composites as cathode materials are systematically discussed and problems associated with these materials are also analyzed. In addition, the research and application of lithium sulfides as cathode materials are also outlined. Finally, the further development of sulfur-based cathode materials and the commercialization of lithium/sulfur batteries are discussed.
\end{abstract}

Key Words: Lithium-sulfur rechargeable battery; Cathode; Sulfur-based composite material; Cycle performance

\section{1 引言}

具有高能量密度、长循环寿命、高安全性、绿色 环保和低成本的二次电池在新能源领域具有巨大的 应用前景. ${ }^{1,2}$ 作为动力电池可广泛地应用于电动工 具、纯电动汽车、混合电动车等; 作为储能电池可应 用于 $3 \mathrm{G}$ 通信、风能和太阳能储能、智能电网等.

目前在手机和笔记本电脑中广泛应用的二次电 池为锂离子电池, 其负极大多采用石墨电极, 正极材
料主要是锂过渡金属氧化物, 包括层状结构的钴酸 锂 $\left(\mathrm{LiCoO}_{2}\right)$ 、钴镍锰三元体系 $\left(\mathrm{LiCo}_{x} \mathrm{Ni}_{y} \mathrm{Mn}_{z} \mathrm{O}_{2}\right.$, 其中 $x+y+z=1)$ 和尖晶石结构的锰酸锂 $\left(\mathrm{LiMn}_{2} \mathrm{O}_{4}\right) . \mathrm{LiCoO}_{2}$ 的电化学性能稳定, 易于合成, 其实际比容量为 150 $\mathrm{mAh} \cdot \mathrm{g}^{-1}$ 左右, 但比容量提高的空间不大, 且钴金属 价格较贵, 成本较高. $\mathrm{LiMn}_{2} \mathrm{O}_{4}$ 的理论比容量为 148 $\mathrm{mAh} \cdot \mathrm{g}^{-1}$, 可逆比容量能够达到 $140 \mathrm{mAh} \cdot \mathrm{g}^{-1}$, 成本 相对 $\mathrm{LiCoO}_{2}$ 低, 但该材料放电过程中结构不稳定,

Received: November 5, 2010; Revised: December 7, 2010; Published on Web: February 28, 2011.

"Corresponding author. Email: wangjiulin@sjtu.edu.cn; Tel: +86-21-54745887.

The project was supported by the National Natural Science Foundation of China (50902095), Shanghai Rising-Star Program, China (07QA14034) and National Key Basic Research Program of China (973) (2007CB209700).

国家自然科学基金(50902095), 上海市青年科技启明星计划(07QA14034)和国家重点基础研究发展规划(973) (2007CB209700)资助项目

(C) Editorial office of Acta Physico-Chimica Sinica 
受温度影响大, 易导致电池性能恶化. ${ }^{3.4}$ 目前由锂过 渡金属氧化物所组成的锂离子电池的能量密度较 低, 约为 $120-150 \mathrm{Wh} \cdot \mathrm{kg}^{-1}$, 并且存在一定的安全隐 患, 阻碍其在动力电池中的广泛应用. 具有橄榄石结 构的磷酸亚铁锂 $\left(\mathrm{LiFePO}_{4}\right)$ 是一种适合用于动力电 池的正极材料, 安全性高, 并且循环寿命长、倍率放 电性能好、成本低. 但 $\mathrm{LiFePO}_{4}$ 存在电导率低, 锂离 子扩散系数小, 以及高低温性能差等缺点..$^{5-7}$

锂硫二次电池是以金属锂作为负极, 单质硫或 硫基复合材料作为正极的二次电池, 其理论能量密 度为 $2600 \mathrm{Wh} \cdot \mathrm{kg}^{-1}$, 实际能量密度目前能达到 300 $\mathrm{Wh} \cdot \mathrm{kg}^{-1}$, 未来几年内极有可能提高到 $600 \mathrm{Wh} \cdot \mathrm{kg}^{-1}$ 左右, 被认为是当前最具研究吸引力的二次电池体 系之一 ${ }^{8-10}$ 硫基正极具有较高的理论比容量, 储量 丰富, 成本低廉. 同时无论硫电极材料本身, 还是在 使用过程中都极少产生对环境有害的物质, 是一种 “绿色电池”. 在目前商业化的锂离子电池中, 锂过渡 金属氧化物正极处于过充电状态时, 会有氧析出, 不 仅会导致电池的容量下降, 严重时还会出现安全问 题; 而硫正极材料不含氧, 不会出现此类问题, 在安 全性方面具有明显的优势. 德国 Siemens 公司曾预 测工作电压在 $2 \mathrm{~V}$ 左右的锂硫电池更加适合未来先 进芯片, 新一代的半导体器件启动电压仅为 1.5-1.8 $\mathrm{V}$, 并消耗极低的能量, 这类低能耗的器件将是未来 芯片领域发展的主要方向之一. ${ }^{11,12}$ 随着微机电系统 (MEMS) 和微小器件的发展, 高能量密度、长循环寿 命的 $2 \mathrm{~V}$ 左右的电池将成为未来先进化学电源发展 的重要方向之一.

可见, 锂硫二次电池能较好地满足未来动力电 池要求中的四个方面, 即高能量密度、较好的安全性 (改善金属锂枝晶后)、绿色环保和低成本; 不足之处 在于金属锂负极和硫基正极材料均存在循环性能 差, 制约了锂硫二次电池的发展, 这也是目前锂硫二 次电池研究的重点. 对于硫基正极, 存在的关键问题 如下: (1) 单质硫在室温下为电子和离子绝缘体, 制 作电极时需添加大量的导电剂(如乙炔黑), 致使电 极体系的能量密度降低; (2) 单质硫在放电过程中会 被还原成易溶的多硫化物, 造成活性物质流失, 并且 多硫化物溶于电解液后, 会增大电解液浓度, 恶化其 离子导电性; (3) 溶于电解液的多硫化物直接接触金 属锂负极, 发生自放电反应; (4) 充放电过程中硫电 极会发生相应的收缩和膨胀, 一定程度上破坏电极 的物理结构. 这些问题均制约了硫基正极的电化学
性能, 导致硫活性物质利用率低、电化学可逆性差以 及容量衰减快等. ${ }^{13-19}$ 因此, 锂硫二次电池正极材料 研究的核心内容在于提高硫基正极的电化学活性、 可逆性和循环稳定性.

本文主要综述和分析了近年来人们在硫基正极 方面所开展的基础性研究和取得的突破性进展, 从 单质硫正极、有机硫化物、硫基复合材料, 以及 $\mathrm{Li}_{2} \mathrm{~S}$ 正极材料四个方面, 深入分析了各种硫基正极的结 构设计、材料制备、反应机理以及充放电特性, 并对 其进一步发展和应用予以展望.

\section{2 单质硫}

单质硫主要以游离态广泛存在于自然界中, 属 于尚未充分利用的资源. 常温下, 单质硫主要以 $\mathrm{S}_{8}$ 的 形态存在. 应用于电池时, 假设放电过程中每个硫原 子的电子转移数为 2 , 则 $\mathrm{S}_{8}$ 的理论比容量为 1672 $\mathrm{mAh} \cdot \mathrm{g}^{-1}$, 理论放电电压为 $2.287 \mathrm{~V}$, 则理论能量密度 为 $3823.9 \mathrm{Wh} \cdot \mathrm{kg}^{-1}$, 是目前已知的除氧气以外能量 密度最高的锂二次电池正极材料.

硫电极一般由单质硫、导电剂和粘合剂三部分 组成. 粘合剂对单质硫正极的电池性能具有较大的 影响, 传统粘合剂的作用在于将电极活性物质与导 电碳粘合在集流体上, 防止电极活性物质脱落; 而 在锂硫二次电池中, 良好的粘合剂除了粘合作用外, 还需能对于硫基活性物质和其放电产物多硫化锂起 到包覆的作用, 从而防止多硫化锂溶解, 提高硫电极 的循环稳定性. 所报道的粘合剂种类比较多, 有聚乙 烯吡咯烷酮(PVP)和聚酰亚胺(PEI), 聚氧化乙烯 (PEO)和聚偏二氟乙烯 $(\mathrm{PVdF})$ 等. ${ }^{20-22} \mathrm{Kim}$ 等 ${ }^{23}$ 对比了 多种粘合剂对于单质硫电极性能的影响, 发现由聚 四氟乙烯(PTFE)和羧甲基纤维素(CMC)组成的混合 粘合剂有利于提高单质硫的电化学利用率, PTFE与 $\mathrm{CMC}$ 均具有较好的机械强度, 有利于抑制单质硫电 极在充放电过程中体积变化带来的破坏性影响. Sun 等 ${ }^{24}$ 用单质硫作正极材料, 比较了 PEO 和明胶 作为粘合剂对硫基正极材料性能的影响. 以明胶为 粘合剂的电池首次放电比容量为 $1132 \mathrm{mAh} \cdot \mathrm{g}^{-1}, 50$ 次循环后比容量依然有 $408 \mathrm{mAh} \cdot \mathrm{g}^{-1}$; 而以聚氧乙烯 为粘合剂的电池首次放电比容量为 $996 \mathrm{mAh} \cdot \mathrm{g}^{-1}, 50$ 次循环后可逆比容量仅为 $300 \mathrm{mAh} \cdot \mathrm{g}^{-1}$ 左右. 如图 1 所示, 50 次循环之后, 以明胶为粘合剂的正极材料 没有出现明显的团聚现象. 明胶是一种水溶性蛋白 质混合物, 对单质硫颗粒具有较好的包络效果, 作为 

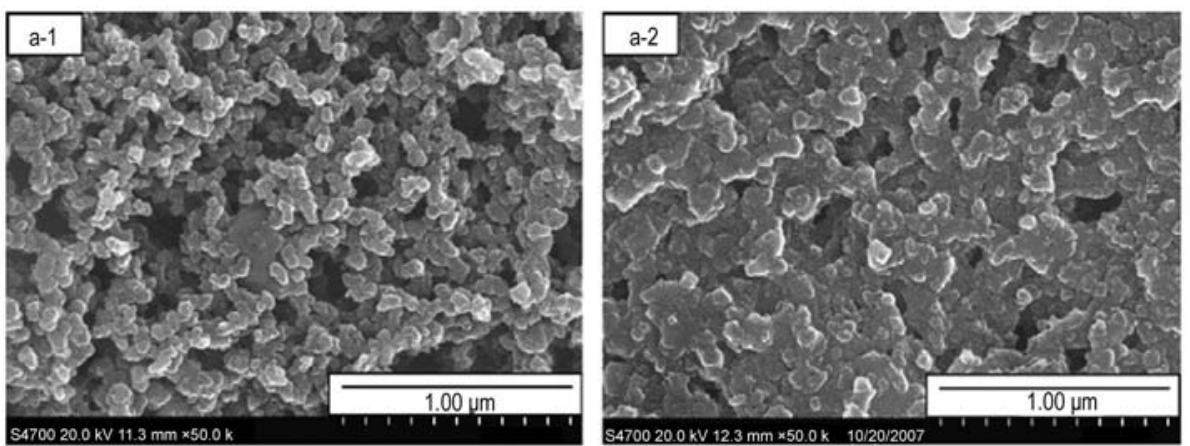

图 1 明胶粘结剂硫复合电极初始电极片(a-1)及 50 次循环后(a-2)的 SEM 图 ${ }^{24}$

Fig.1 SEM images of the gelatin binder-sulfur composite cathode as prepared (a-1) and after 50 cycles (a-2)

粘合剂可使硫基材料表现出良好的电化学性能,但 明胶在电解液中长时间的稳定性有待进一步研究.

Sun 研究小组 ${ }^{25}$ 进一步采用冷冻干燥法制备多 孔硫电极, 显著改善了电极的电化学性能. 在冷冻条 件下明胶溶液会形成冰晶, 随后在真空干燥过程中 冰晶消失, 留下微孔(见图 2). 冷冻干燥法(FD)得到 的硫材料循环性能较普通升温干燥法(ETD)制备的 材料好, 50 次循环后其比容量仍然保持在 $626 \mathrm{mAh}$. $\mathrm{g}^{-1}$ (见图 3). 通过明胶溶液冷冻干燥造孔可以有效地 增大电极的比表面积, 提高固液界面接触, 从而改善 了电极中单质硫的电化学活性; 大量的孔洞也有利 于缓冲电极的体积变化, 起到稳定循环性能的作用. Zhang 等 ${ }^{26}$ 研究了明胶溶液的 $\mathrm{pH}$ 值对硫正极材料性 能的影响. 当明胶溶液的 $\mathrm{pH}$ 值为 10.0 时, 硫正极表 现出良好的电化学性能.

电解质体系对于单质硫电极的电化学活性和可 逆性具有很大的影响, 目前锂离子电池常用的 EC-DMC-LiPF 6 电解质对于单质硫电极针化现象严 重, 以二氧五环(DOL)为主的有机溶剂体系能有效 地提高单质硫正极的电化学性能. ${ }^{27,28}$ 而采用 PEO 聚 合物电解质、 ${ }^{29-31}$ 凝胶电解质、 ${ }^{32,33}$ 离子液体 ${ }^{34,35}$ 以及

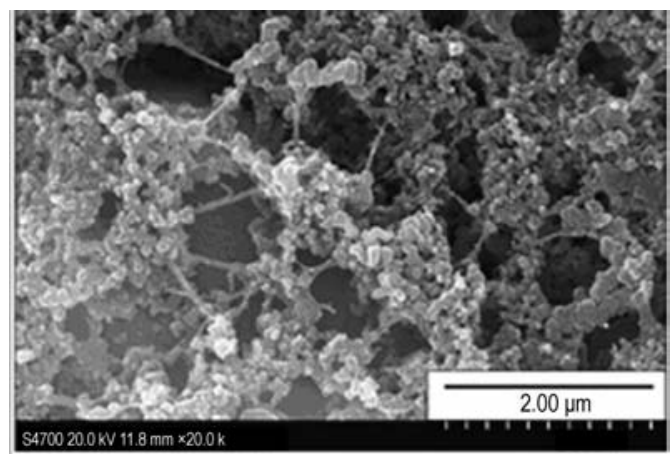

图 2 冷冻干燥法制备的复合正极的 SEM 图 ${ }^{25}$

Fig.2 SEM images of the composite cathodes by freeze drying method ${ }^{25}$
纯固体电解质 ${ }^{36}$ 均对抑制放电产物多硫化物的溶解 和改善单质硫电极的循环稳定性具有较为显著的作 用, 但这些电解质体系室温导电率低, 限制了锂硫二 次电池的功率特性.

\section{3 有机硫化物}

有机硫化物作为电池的正极材料, 可以通过 $\mathrm{S}-\mathrm{S}$ 键的断裂与键合进行能量释放与储存, 即在电 池中进行放电和充电. 有机硫化物可能存在单体、 二聚体、多聚体等多种形式, 具体存在形式决定于 电极电位. 有机硫化物具有较高的能量密度, 如果 采用分子中含有多个硫原子的聚硫化合物, 能量密 度将会更高. 假设平均放电电压为 $2.5 \mathrm{~V}, 5$-甲基- 1 , 3,4-噻二唑-2-颈醇(MTT)二聚体的理论能量密度在 1500-3500 Wh $\cdot \mathrm{kg}^{-1}$ 之间. $\mathrm{Li} / \mathrm{DMcT}(2,5$-二颈基-1,3, 4-噻二唑)-二硫化合物、 $\mathrm{Li} / \mathrm{DMcT}$-三硫化合物和 $\mathrm{Li} /$ DMcT-四硫化合物电池的实际能量密度分别为 $385 、 590$ 和 $700 \mathrm{Wh} \cdot \mathrm{kg}^{-1}$. 此外, 有机硫化物还具有 价格低、毒性小、活性物质分子结构易于设计等优 点. ${ }^{37-42}$

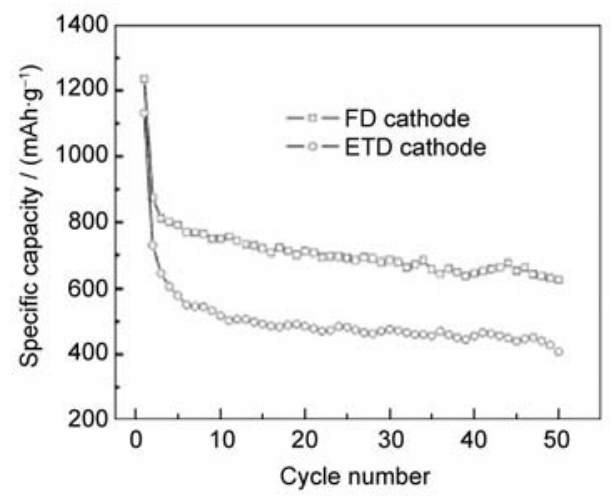

图 3 ETD 和 FD 正极的循环性能 ${ }^{25}$

Fig.3 Cycle performance of the ETD and FD cathodes ${ }^{25}$ current density: $200 \mathrm{~mA} \cdot \mathrm{g}^{-1}$ 
Skotheim 等 ${ }^{43-45}$ 设计并合成了聚碳硫化物材料 $\left(\mathrm{CS}_{x}\right)_{n}$ (其中, $2<x<50, n>2$ ). 这些有机硫化物的可逆 容量都比较低, 虽然材料中硫含量较高, 但 $\mathrm{C}-\mathrm{S}$ 键 作用力太强, 导致电化学活性差. 将硫嫁接到芳香烃 环上形成多硫化合物, ${ }^{46}$ 该材料由于含硫相对较高, 初始放电容量达 $1000 \mathrm{mAh} \cdot \mathrm{g}^{-1}$. 但芳香环并不能起 到导电的作用, 将限制充放电电流, 影响电池的功率 特性.

以 DMcT 为代表的具有线型结构的有机硫化物 被认为是最具前景的有机硫化物正极材料之一. ${ }^{47,48}$ Oyama ${ }^{49-52}$ 和 $\mathrm{Yu}^{53,54}$ 等研究发现聚苯胺(PAn) 可以大 大地催化 DMcT 的氧化还原速率, 尤其是电化学方 法制备的 PAn 效果更好. PAn 本身也具有电化学活 性, 并且掺杂后具有良好的电子导电性, 在复合电极 中, 起到分子集流体的作用, 克服了有机硫化物导电 性差这一缺点. 将 DMcT 和 PAn 溶解在 $N$-甲基吡咯 烷酮(NMP)中, 可使二者达到分子水平上的接触. 小 电流充电时, 正极比容量为 $185 \mathrm{mAh} \cdot \mathrm{g}^{-1}$, 平均放电 电压在 $3.4 \mathrm{~V}$, 重量比能量为 $600 \mathrm{Wh} \cdot \mathrm{kg}^{-1}$. 当抽提掉 残余的 NMP 后, 比能量可达 $900 \mathrm{Wh} \cdot \mathrm{kg}^{-1}$. 如此高能 量密度的复合正极材料十分适合于对重量要求严格 的场合, 如卫星、航天飞行器用电源等. Park 等 ${ }^{55}$ 将 聚苯胺(PAn) 和纳米 $\mathrm{Ag}$ 粒子引入到 DMcT 中, 进一 步提高材料的电化学活性和反应速率. 获得的薄膜 正极材料的稳定放电比容量可达 $216 \mathrm{mAh} \cdot \mathrm{g}^{-1}$, 高于 不含 $\mathrm{Ag}$ 粒子的 DMcT-PAn 材料. 原因在于聚苯胺 (PAn) 可以增强材料的导电性, 而纳米 $\mathrm{Ag}$ 粒子同时 兼具导电和催化作用, 二者可以加速有机硫-导电 聚合物(DMcT-PAn)的氧化还原速率, 提高其电化 学活性.

Xue 等 ${ }^{56}$ 用葱制备了一种新型的有机硫化物聚 六硫葱 $(\mathrm{ABTH})$, 通过氧化偶联聚合反应得到聚葱 (PABTH). 元素分析表明 PABTH 中的硫含量达到 $60 \%(w)$, 进一步表征发现 ABTH 和 PABTH 含有 $\mathrm{C}=\mathrm{S}$ 和 $\mathrm{C}-\mathrm{S}$ 键. 采用含 $1 \mathrm{~mol} \cdot \mathrm{L}^{-1} \mathrm{LiClO}_{4}$ 的 $\mathrm{EC} /$ $\mathrm{DMC}$ 电解液组装成扣式电池, 测试其首次放电容量 为 $300 \mathrm{mAh} \cdot \mathrm{g}^{-1}, 5$ 次循环后容量在 $250 \mathrm{mAh} \cdot \mathrm{g}^{-1}$ 左 右. $\mathrm{Li}^{\text {等 }}{ }^{57}$ 进一步探索了 PABTH 在不同电解液中的 电化学特性. 采用 $1 \mathrm{~mol} \cdot \mathrm{L}^{-1} \mathrm{LiTFSI}$ 的二氧戊环 (DXL)/乙二醇二甲醚(DME)(体积比 $2: 1$ )电解液, 虽 然首次放电容量降低到 $290 \mathrm{mAh} \cdot \mathrm{g}^{-1}$, 但是在其后的 循环中容量比较稳定, 多次循环后依然维持在 250 $\mathrm{mAh} \cdot \mathrm{g}^{-1}$, 容量衰减较小. 表明 PABTH 的电化学性

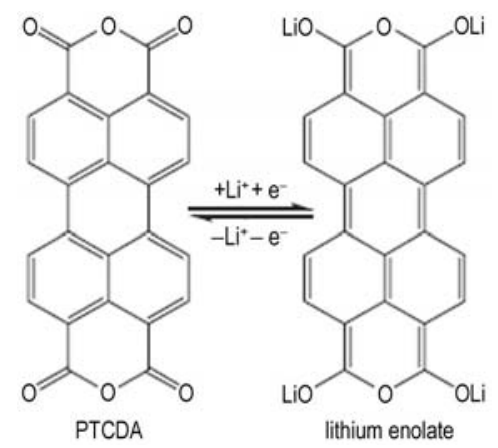

图 4 锂离子在PTCDA 中可逆的嵌入和脱嵌反应示意图 ${ }^{58}$

Fig.4 Schematic diagram for the proposed reversible Li-ion insertion/deinsertion in PTCDA ${ }^{58}$

能与采用的电解液有着密切关系, 这点与单质硫电 极类似, EC/DMC 系列的电解质易在硫基正极表面 形成较厚的针化膜, 而 DOL 为主的电解质体系对于 放电产物具有较好的界面相容性, 有利于减小界面 电阻, 提高电极的电化学活性和循环稳定性. ${ }^{27,28}$

Han 等 ${ }^{58}$ 研究了二菜嵌苯四羧酸双䣶(PTCDA) 及其硫化物的电化学性质, PTCDA 的碳氧双键可以 发生醇化反应, 提供了 $\mathrm{Li}$ 离子嵌入和脱嵌的位点, 如图 4 所示, 在放电即还原过程中, 每个羧基可以接 受一个电子, 并同时接受一个 $\mathrm{Li}$ 离子形成锂烯醇, 充电即氧化过程与此相反. 将 PTCDA 和硫高温复 合形成 PTCDA 的硫化物, 可以得到电化学性能更 好的正极材料一一硫化二䒺嵌苯四羧酸双酐(PTC$\mathrm{DA} / \mathrm{S}$ ). 在 450 和 $500{ }^{\circ} \mathrm{C}$ 下分别制备的 PTCDA 硫化 物, 其形貌与 PTCDA 相似, 电化学性能见图 5 和图 6, PTCDA 的初始放电比容量为 $120-130 \mathrm{mAh} \cdot \mathrm{g}^{-1}$, 之 后容量逐步衰减, 90 次降到初始容量的 $50 \%$ 以下. 而与硫复合后, 在初始的 30 次循环中, 两种温度下 得到的材料容量衰减均较快, 随后循环容量得到恢 复, 对于 $500{ }^{\circ} \mathrm{C}$ 处理的材料, 后期循环容量甚至超 过了初始容量. 可见, PTCDA 经过硫化处理后, 电化 学性能明显提高. 从分子结构上看, PTCDA 中的电 子只能通过层间 $\pi-\pi$ 键传导, 而 PTCDA/S 材料, 电 子除了可通过层间 $\pi-\pi$ 键传导外, 还可通过硫醚键 进行传导, 导电性明显得到改善; 同时硫醚键可将 放电产物束缚在 PTCDA 分子上, 有效地抑制反应 物的溶解, 提高电极的循环稳定性. 这一研究结果为 设计开发具有新型结构的有机硫化物正极材料提供 了很好的参考, 但有关材料循环过程中出现的先衰 减后增加的现象有待进一步分析.

\section{4 硫基复合材料}




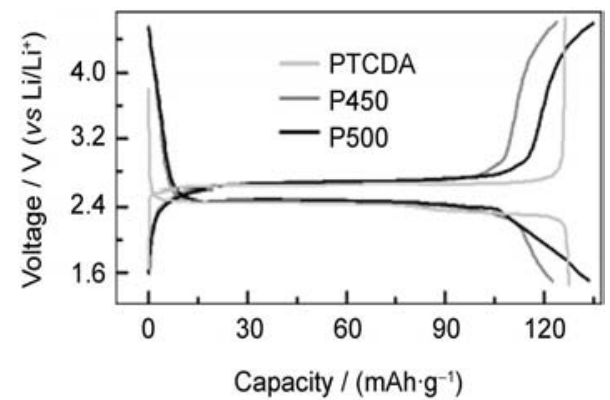

图 5 PTCDA 及其硫化物的首次充放电的电压曲线 ${ }^{58}$

Fig.5 Voltage profiles of the initial charge/discharge processes for PTCDA and the sulfide polymers ${ }^{58}$ current density: $100 \mathrm{~mA} \cdot \mathrm{g}^{-1}$; P450, P500: sulfide polymer obtained at $450,500^{\circ} \mathrm{C}$

\section{1 多孔碳/硫复合材料}

在锂硫二次电池体系中, 由于充放电过程中电 极体积变化导致结构发生崩塌, 形成电化学可逆性 差的 $\mathrm{Li}_{2} \mathrm{~S}$, 放电产物多硫化物易于溶解到电解质中 等这些问题均导致了单质硫正极组成的电池容量衰 减明显. 59 我们在 2002 年提出了采用吸附性强、导电 性好的活性碳材料与单质硫复合, 将单质硫以纳米 级尺寸牢牢地吸附在活性碳的孔隙或孔道中, 一方 面通过纳米化提高单质硫的电化学活性, 并增强硫 基正极材料的电子导电性, 另一方面保证了复合材 料的结构稳定性, 试图抑制电极材料在电解液中的 溶解. ${ }^{60,61}$ 介孔碳和碳纳米管均可作为具有大比表面 积的电子导电基体, 单质硫吸附或镶嵌入孔道中形 成电化学性能良好的碳基硫复合材料. ${ }^{62-65}$

Zheng 等 ${ }^{6}$ 将多壁碳纳米管(MWCNTs) 与单质 硫混合后在氩气气氛下加热至 $150{ }^{\circ} \mathrm{C}$ 并恒温 $10 \mathrm{~h}$, 使硫在高温下融化并扩散入碳纳米管的小孔中, 随 后升温至 $350^{\circ} \mathrm{C}$ 并保持 $4 \mathrm{~h}$, 使覆盖在碳纳米管表面 的硫蒸发掉, 最终制得碳纳米管/硫复合正极材料. 图 7 表明升华硫很好地嵌入到了碳纳米管的纳米孔

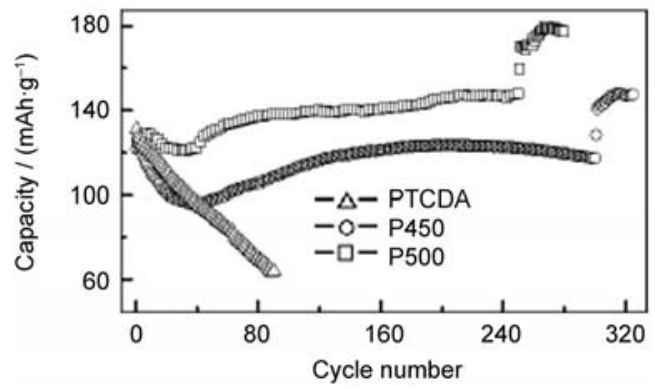

图 6 PTCDA 及其硫化物的循环曲线 ${ }^{58}$

Fig.6 Discharge capacity versus cycle number for PTCDA and the sulfide polymers ${ }^{58}$ current density: $100 \mathrm{~mA} \cdot \mathrm{g}^{-1}$

和微孔中. 电池性能表明, 60 次循环后碳纳米管/硫 复合正极材料的比容量依然可达 $500 \mathrm{mAh} \cdot \mathrm{g}^{-1}$, 平均 衰减率低于 $3.1 \%$, 性能明显优于不加碳纳米管的传 统单质硫正极材料, 可见, CNTs 能有效地提高单质 硫电极的电化学活性, 并能保持电极结构稳定.

乙炔黑是一种常用的电池材料导电剂, 除具有 优良的导电性外, 还有吸液性强、弹性高等特点, 与 电池材料复合能提高硫基正极的电化学性能. Zhang 等 ${ }^{67}$ 将乙炔黑和硫混合后在氩气保护下进行 热处理, 得到硫含量为 $36 \%(w)$ 的复合材料. SEM 结 果显示纳米级的硫嵌入到空间呈链状排列的乙炔黑 颗粒中 (见图 8). 材料的首次放电容量为 $934.9 \mathrm{mAh}$. $\mathrm{g}^{-1}$, 第二次放电容量衰减为 $636.2 \mathrm{mAh} \cdot \mathrm{g}^{-1}$, 之后衰 减变缓(衰减率小于 $1 \%$ ), 50 次循环后比容量依然保 持有 $500 \mathrm{mAh} \cdot \mathrm{g}^{-1}$. 乙炔黑的多孔结构可以有效抑制 多硫化物在有机电解质中的溶解, 并能缓解电极充 放电过程中的体积变化的影响, 稳定电极的结构.

与传统的碳材料相比, 设计和合成具有特殊结 构的碳材料, 并与硫复合, 通常可以达到更加显著的 效果. Lai 等 ${ }^{68}$ 合成了一种新型的多孔碳, 将 PAN 和 碳酸钠混合后溶于 $N, N$-二甲基酰胺溶剂中, 待溶剂
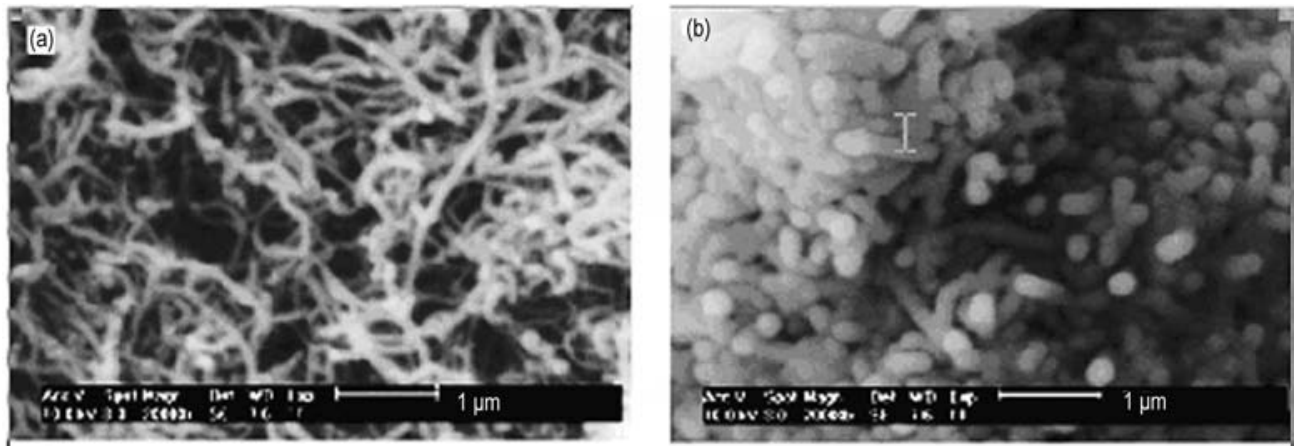

图 7 电极材料的 SEM 图谱 ${ }^{60}$

Fig.7 SEM images of cathode material ${ }^{66}$

(a) MWCNTs; (b) MSN cathode. MWCNTs: mutil-walled carbon nanotubes; MSN: sulfur nanocomposite 


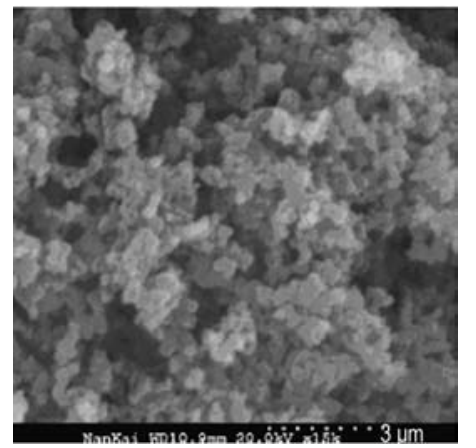

图 8 乙炔黑/硫复合材料的 TEM 图谱 ${ }^{67}$

Fig.8 TEM image of sulfur-acetylene black composite material $^{67}$

蒸发后, 在氩气气氛下热处理得到多孔碳材料 (HPC), 碳酸钠的作用在于造孔. 将得到的碳材料洗 涤并干燥后, 与单质硫混合, 在氩气气氛下加热到 $150{ }^{\circ} \mathrm{C}$ 并保持 $6 \mathrm{~h}$, 这样单质硫可以扩散到多孔碳材 料的孔中, 然后再加热到 $300^{\circ} \mathrm{C}$ 保持 $3 \mathrm{~h}$, 以蒸发掉 复合材料表面多余的硫，最后制得硫含量 57\% (w) 的复合硫正极材料, 其形貌见图 9 . 在 $40 \mathrm{~mA} \cdot \mathrm{g}^{-1}$ 的 电流密度下充放电, 电池首次放电比容量达到 1031 $\mathrm{mAh} \cdot \mathrm{g}^{-1}, 84$ 次循环后, 比容量依然保持在 745 $\mathrm{mAh} \cdot \mathrm{g}^{-1}$, 此时将电池放置三天后继续检测, 发现放

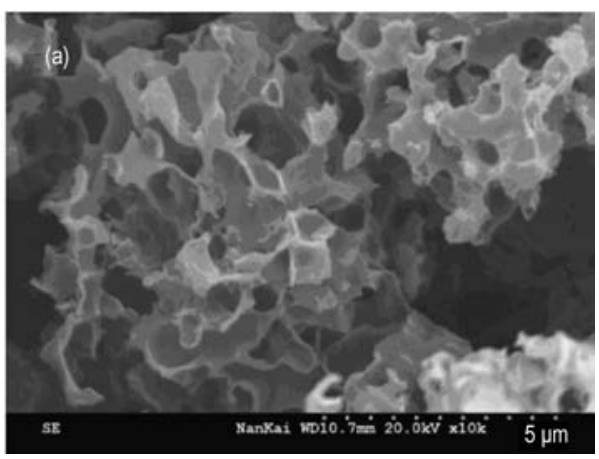

电比容量可恢复到 $824 \mathrm{mAh} \cdot \mathrm{g}^{-1}$, 且 110 次循环后, 可逆比容量依然可维持在 $770 \mathrm{mAh} \cdot \mathrm{g}^{-1}$. 分析认为材 料形成的多硫化锂可以较稳定地存在于多孔碳亚微 米和纳米孔中, 从而减少电池的容量衰减.

最近在锂硫二次电池中取得较大突破性进展的 当属加拿大的 Nazar 研究小组, ${ }^{69}$ 他们采用 SBA-15 模板制备了介孔碳 CMK-3, 其中碳棒的直径约为 $6.5 \mathrm{~nm}$, 间隙宽度约为 $3 \mathrm{~nm}$, 并且孔间隙中还贯穿有 碳纳米纤维, 保持 CMK-3 结构的稳定. 随后将 CMK-3 和硫按照质量比 3:7 混合, 并在 $155^{\circ} \mathrm{C}$ 下进 行热处理. 通过毛细作用使熔融态的硫渗入到 CMK-3 的孔道中, 最终得到硫含量为 70\% (w) 的有 序排列的 CMK-3/硫复合材料, 具体过程见图 10. 此 时材料中的硫并未完全充满 CMK-3 的孔道, 留有的 空间用以适应充放电过程中产生的体积变化. 电池 性能结果表明, 硫基正极的首次放电容量达到 1000 $\mathrm{mAh} \cdot \mathrm{g}^{-1}, 20$ 次循环后容量维持在 $800 \mathrm{mAh} \cdot \mathrm{g}^{-1}$. 为 了进一步减少循环过程中多硫化物的溶解, 在 S-CMK-3 复合物的表面包覆了聚乙二醇(PEG)后, 首次放电容量提高到 $1320 \mathrm{mAh} \cdot \mathrm{g}^{-1}, 10$ 次循环后其 容量维持在 $1100 \mathrm{mAh} \cdot \mathrm{g}^{-1}$ (图 11). 使用高分辨率扫

图 9 HPC(a)和含硫量 $57 \%(w)$ 的 S/HPC(b) 的 SEM 图 ${ }^{68}$

Fig.9 SEM images of HPC (a) and sulfur/HPC composite material with $57 \%(w)$ sulfur $(b)^{68}$

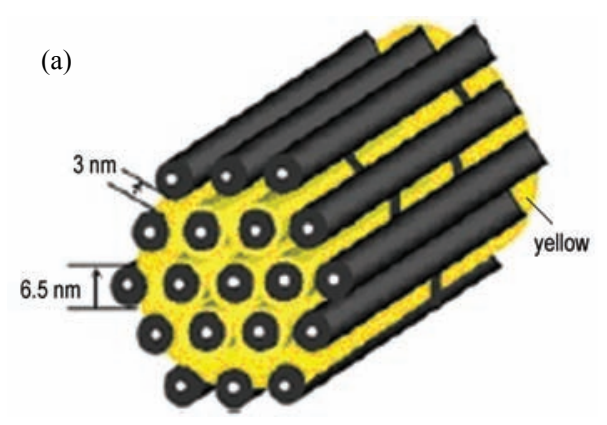

(b)
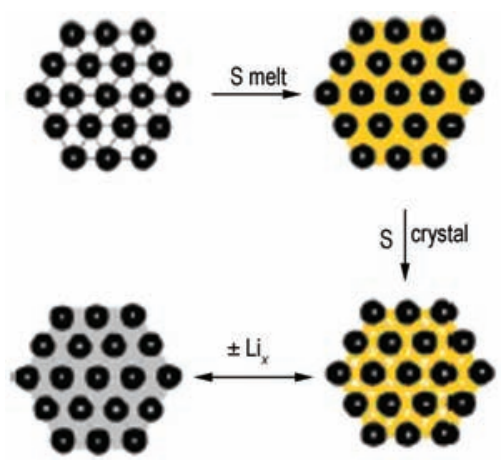

图 10 填充了单质硫的介孔碳(CMK-3)(a)和单质硫融入介孔碳中结晶致密化、充放电示意图(b) ${ }^{69}$

Fig.10 Schematic diagrams of the sulfur (yellow) confined in the interconnected pore structure of mesoporous carbon, CMK-3 (a) and composite synthesis by impregnation of molten sulfur, followed by discharging-charging process (b) ${ }^{69}$ 


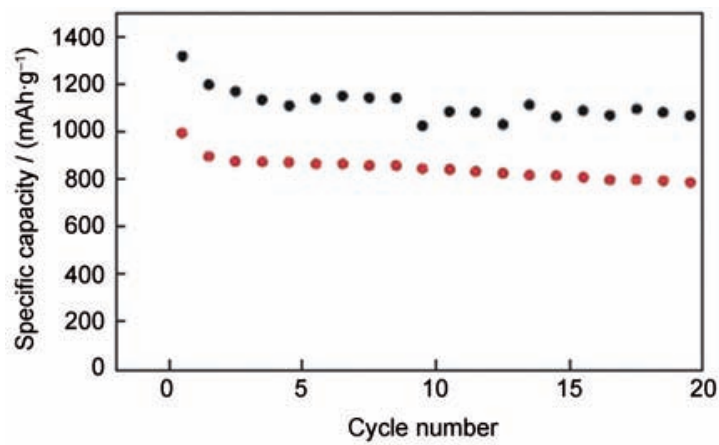

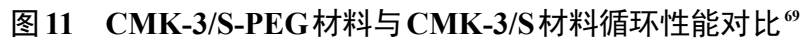

Fig.11 Cycling stability comparison of CMK-3/S-PEG (upper points) versus $\mathrm{CMK}-3 / \mathrm{S}$ (lower points) at room temperature $^{69}$

current density: $168 \mathrm{~mA} \cdot \mathrm{g}^{-1}$

描电镜观察充放电过程对电极形貌的影响发现, 未 包覆的 S-CMK-3 材料 15 次循环后, 颗粒明显收缩, 且表面沉积有部分难溶物质, 而包覆 PEG 层的材料 循环前后形态未发生明显变化. 可见, 将单质硫镶嵌 入纳米孔道中可以有效地提高硫电极的电化学活性 和充放电可逆性, 并利用特殊的孔道结构缓解电极 体积变化的影响, 同时采用包覆技术抑制放电产物 的溶解, 三方面的技术协同作用能显著地提高硫基 正极的电化学性能. 但从前 20 次循环来看, 硫基正 极的容量衰减还比较明显, 这方面可能与热处理过 程中表面残余的吸附硫有关, 可望通过优化表面包 覆材料得到改善. 另外, 介孔碳不仅在单质硫复合电 极中表现出优异的性能, 而且在抑制硅基负极体积 变化方面也具有很好的效果. ${ }^{70}$

Liang 等 ${ }^{71}$ 采用软模板法制备了均匀分布的、孔 径大小约为 $7.3 \mathrm{~nm}$ 的中孔碳, 之后用 $\mathrm{KOH}$ 对材料作 进一步处理, 中孔之间又形成孔径小于 $2 \mathrm{~nm}$ 的微 孔, 最终合成一种具有分级孔道结构的碳材料. 其 中, 材料中直径为 $7.3 \mathrm{~nm}$ 的中孔可以作为锂离子的 通道, 并吸附电化学反应中产生的多硫化物, 提高电 化学和循环性能; 而微孔则可作为单质硫的微反应 器, 其较高的比表面积可以显著提高活性物质硫的 反应活性, 最终使复合材料兼具两种孔结构的优点. 将此种特殊结构的碳材料反复放入含硫 $10 \%(w)$ 的 $\mathrm{CS}_{2}$ 溶液中并浸润、干燥, 最终得到不同硫含量的介 孔碳/硫复合材料(图 12). 当含硫量为 $11.7 \%(w)$ (即 图 13 中的 S-C01)时, 电池初始放电容量(以单质硫 计算)达 $1585 \mathrm{mAh} \cdot \mathrm{g}^{-1}, 30$ 次循环后容量依然维持在 $805 \mathrm{mAh} \cdot \mathrm{g}^{-1}$.

\section{2 聚合物/硫正极材料}

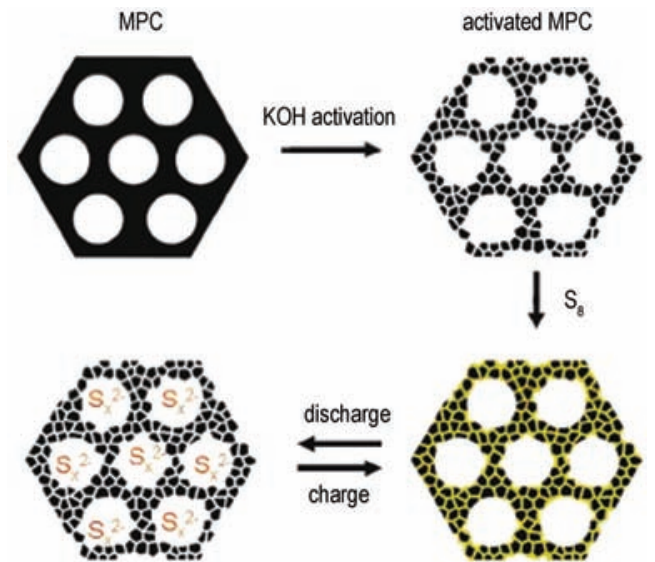

图 12 用分级孔道结构的双孔碳做支撑物的 $S / C$ 复合材料 制备示意图 ${ }^{71}$

Fig.12 Illustration of the $S / C$ composite cathode material using a bimodal porous carbon as the support ${ }^{71}$

将高分子聚合物引入硫基材料中通常可有效地 克服单质硫电子和离子绝缘这一缺点, 同时以聚合 物作为复合材料的基体, 可以达到提高活性硫利用 率, 稳固电极结构和改善循环稳定性的目的.

Zhu 等 ${ }^{72}$ 采用两种方法制备出硫-聚氧乙烯 (SPEO)复合物,一种方法是将 $\mathrm{S}$ 和 PEO 球磨混合得 $S P M$ 复合物; 另一种方法是将 $S$ 和 PEO 在密闭容器 中加热得 SPT 复合物. 采用 PEO 全固态电解质组装 成锂硫二次电池, $\mathrm{Li} / \mathrm{SPM}$ 聚合物电池的放电电压平 台经 10 次循环后从 $2.1 \mathrm{~V}$ 下降到 $1.9 \mathrm{~V}$, 对应放电容 量从 $609 \mathrm{mAh} \cdot \mathrm{g}^{-1}$ 衰减至 $280 \mathrm{mAh} \cdot \mathrm{g}^{-1}, 50$ 次循环后 已无明显的电压平台, 而充电电压平台则逐渐升高. 相对应, $\mathrm{Li} / \mathrm{SPT}$ 聚合物电池的充放电电压平台一直 比较稳定, 50 次循环之后依然比较明显, 且容量衰 减较为缓慢. 球磨法制备的复合材料中单质硫分散 性较差, 在循环过程中单质硫和多硫化锂易聚集成

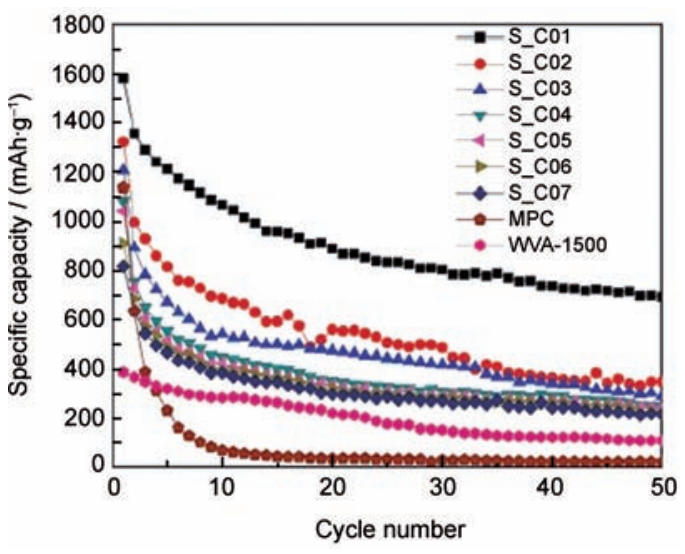

图 $13 \mathrm{~S} / \mathrm{C}$ 复合材料循环性能 ${ }^{71}$

Fig.13 Cycle performances of $\mathrm{S} / \mathrm{C}$ composites $^{71}$ 
团, 导致内阻变大, 极化程度增加, 容量衰减较快; 而采用加热处理后, 单质硫的分散性明显提高, 充放 电循环中硫和多硫化锂的聚集程度也得以有效缓 解. 综合分析不难得出, 设法将单质硫和多硫化锂固 定在聚合物基底材料上, 可以大大提高电池的性能.

我们将聚丙烯腈(PAN)与硫混合, 在 $280-300{ }^{\circ} \mathrm{C}$ 氮气气氛下加热 6-8 h, 制得一种新型的 $\mathrm{PAN} / \mathrm{S}$ 复 合材料. ${ }^{73-79}$ 加热过程中反应机理为: 在单质硫的催 化作用下, 聚丙烯腈发生脱氢形成类似聚乙炔结构 的主链, 并且侧链氰基发生环化, 同时熔融态的单质 硫嵌入聚合物基体中 (图 14). 当热处理温度低于 $350{ }^{\circ} \mathrm{C}$ 时, 采用拉曼(Raman)、固相核磁共振(NMR) 等测试技术未能检测到 PAN $/ \mathrm{S}$ 复合材料中存在 $\mathrm{C}-$ $\mathrm{S}$ 化学键; 当处理温度高于 $400{ }^{\circ} \mathrm{C}$ 时, PAN 与 $\mathrm{S}$ 形成 了明显的 $\mathrm{C}-\mathrm{S}$ 化学键. ${ }^{80-82}$ 对于 $350^{\circ} \mathrm{C}$ 以下获得的 $\mathrm{PAN} / \mathrm{S}$ 复合材料, 猜测 PAN 与 $\mathrm{S}$ 之间形成具有一定 相互作用力的络合, 其作用力大小介于范德华力键 与化学键之间, 从而实现 $\mathrm{PAN} / \mathrm{S}$ 材料中二者分子水 平上的复合. 以金属锂为负极, $1 \mathrm{~mol} \cdot \mathrm{L}^{-1} \mathrm{LiPF}_{6}$ 的 $\mathrm{EC} / \mathrm{DMC}$ 作为电解质组装电池, $\mathrm{PAN} / \mathrm{S}$ 复合材料的 首次放电比容量为 $850 \mathrm{mAh} \cdot \mathrm{g}^{-1}$ ( 以 $\mathrm{PAN} / \mathrm{S}$ 复合材 料作为计算依据, 而非单质硫), 50 次循环后比容量 仍保持在 $600 \mathrm{mAh} \cdot \mathrm{g}^{-1}$ 以上, 如果仅以复合材料中 硫的质量计算容量, 比容量高达 $1550 \mathrm{mAh} \cdot \mathrm{g}^{-1}$, 硫的 电化学利用率达到 $92 \%$ 左右, 并且除第一放电外, 充 放电效率接近 100\%, 这点对于实际应用十分重要. Yurity等公司 ${ }^{83}$ 报道锂硫二次电池具有良好的内循 环性能, 可防止过充电, 提高电池的安全性能. 所谓 的内循环是指充电过程中多硫化物迁移到负极, 与 金属锂自放电, 然后再迁移到正极, 这一过程使得电 池充放电效率低, 对于实际应用不利. 清华大学何向 明等 ${ }^{84-87}$ 进一步研究聚丙烯腈/硫基复合材料的充放 电特性, 以及聚丙烯腈前驱体形貌的影响.

对于单质硫复合材料, 由于大量放电产物多硫 化物的溶解, 电池容量衰减明显, 与之相对应的一系 列改进措施, 如分散、包覆等效果并不佳. 不同于单 质硫复合材料, PAN/S 复合材料自放电率低, 活性硫 和多硫化物在复合材料中的状态稳定, 采用环糊精

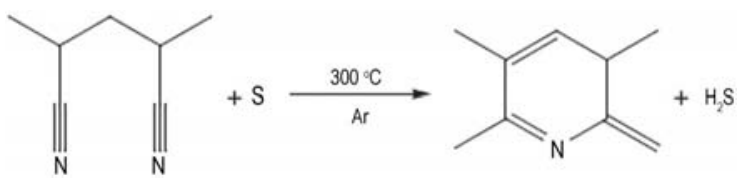

图 14 PAN 和硫反应机理 ${ }^{73}$

Fig.14 Reaction mechanism of PAN and sulfur ${ }^{73}$
作为硫基正极粘合剂, 获得了循环性能十分稳定的 锂硫二次电池, 其自放电率甚至低于目前的锂离子 电池. 88.89 但 PAN/S 复合材料存在电子导电性差, 振 实密度偏低等缺陷. 最近, 我们通过合成 PAN 均聚 物和共聚物, 调控聚合物的形貌, 并将碳纳米管引入 到 PAN/S 复合材料中, 大大提高了锂硫二次电池的 倍率特性, 可在 $7 C$ 下较好地放电..$^{0-92}$

聚吡咯(PPy)是一种典型的导电高聚物, 作为电 化学辅助材料, PPy 除保证复合材料良好的导电性 外, 还对其中的活性物质起到一定的分散和吸附作 用, 从多方面改进材料的性能. ${ }^{93}$ Sun 等 ${ }^{94}$ 首先采用表 面活性剂诱导法制备出具有网状结构的 PPy, 将其 与单质硫按质量比 $1: 2$ 混合, 在氩气环境下加热至 $150{ }^{\circ} \mathrm{C}$ 并保持 $2 \mathrm{~h}$ 获得 S-PPy 复合材料, 其首次放电 容量为 $1222 \mathrm{mAh} \cdot \mathrm{g}^{-1}$, 第 20 次循环的容量为 570 $\mathrm{mAh} \cdot \mathrm{g}^{-1}$, 高于作为对比的单质硫正极材料. 制备过 程中 PPy 和硫之间并没有发生化学反应, 单质硫熔 融扩散到 PPy 的纳米孔和微孔后, 其导电性能得到 显著提高; 同时, PPy 较大的比表面积可以吸附放电 过程产生的多硫化物, 减少其在电解液中的溶解, 从 而降低电池比容量的衰减.

$\mathrm{Wu}$ 等 ${ }^{95}$ 用化学氧化法制得较纯的聚噻吩/硫复 合材料(S-PTh). SEM 照片显示 S-PTh复合材料表面 呈多孔状结构, 其中 PTh 可通过减少颗粒间的接触 电阻提高材料的导电性, 同时增加电极材料和电解 液的接触面积, 增强电极的反应活性. 复合材料中 PTh 能较好地包覆单质硫, 表现良好的循环性能, 首 次放电容量达 $1168 \mathrm{mAh} \cdot \mathrm{g}^{-1}, 50$ 次循环后容量仍维 持有 $819 \mathrm{mAh} \cdot \mathrm{g}^{-1}$. 同样可以得出, PTh 的多孔结构 既有利于电解液在电极中的扩散, 还可以吸附循环 过程中产生的多硫化物.

\section{5 硫化锂正极材料}

锂硫电池体系中, 由于硫基正极不含锂, 需采用 金属锂作为负极来提供锂源. 然而在循环过程中, 金 属锂负极易在表面生成锂枝晶和粉化, 不但存在安 全隐患, 而且耗尽电解液导致锂硫二次电池提前失 效, 限制了锂硫电池的应用. 研究者采用 $\mathrm{Li}_{2} \mathrm{~S}$ 代替硫 基正极, 或将硫基正极预先锂化后, 采用碳负极, ${ }^{96}$ 或 具有较高容量的硅、锡作为负极材料, 目的在于消除 金属锂负极的影响. 硫化锂正极的理论容量较高, 为 $1166 \mathrm{mAh} \cdot \mathrm{g}^{-1}$, 但它和硫电极一样也是绝缘性材料, 需要加入导电添加剂, 并进行特殊的包覆处理提高 
其电化学活性.

Zhou 等 ${ }^{97}$ 将 $\mathrm{Li}_{2} \mathrm{~S}$ 和 $\mathrm{Co}$ 混合后采用脉冲激光沉 淀法(PLD) 制得 $\mathrm{Li}_{2} \mathrm{~S}$ 和 Co 混合材料, 以金属锂作负 极, 掺氮的 $\mathrm{Li}_{3} \mathrm{PO}_{4}(\mathrm{LiPON})$ 作为电解质组装成全固态 的锂硫二次电池, 首次放电比容量为 $1257 \mathrm{mAh} \cdot \mathrm{g}^{-1}$, 第二次为 $819 \mathrm{mAh} \cdot \mathrm{g}^{-1}$, 循环 22 次后比容量仍保持 有 $550 \mathrm{mAh} \cdot \mathrm{g}^{-1}$; 而用纯 $\mathrm{Li}_{2} \mathrm{~S}$ 作正极的半电池, 其首 放容量仅为 $380 \mathrm{mAh} \cdot \mathrm{g}^{-1}$, 在随后的循环中, 比容量 很快降到 $100 \mathrm{mAh} \cdot \mathrm{g}^{-1}$ 以下. 纯的 $\mathrm{Li}_{2} \mathrm{~S}$ 材料电子导电 性差, 电化学反应可逆性差, 而 Co 的加入可以大大 提高 $\mathrm{Li}_{2} \mathrm{~S}$ 的电化学性能.

Takeuchi 等 ${ }^{98}$ 采用火花等离子体烧结(SPS)法制 备出一种 $\mathrm{Li}_{2} \mathrm{~S}-\mathrm{C}$ 复合材料. 将 $\mathrm{Li}_{2} \mathrm{~S}$ 和乙炔黑球磨混 合后倒入石墨模具中, 装入 SPS 设备中并提供氩气 环境, 给予直流电流, 温度控制在 $400-1000{ }^{\circ} \mathrm{C}$, 可 以制得不同温度处理下的 $\mathrm{Li}_{2} \mathrm{~S}-\mathrm{C}$ 复合材料. $600{ }^{\circ} \mathrm{C}$ 处理下制得的复合材料首次充/放电比容量分别达 1200 和 $200 \mathrm{mAh} \cdot \mathrm{g}^{-1}$.

同样借助于介孔碳材料, Yang 等 ${ }^{99}$ 将单质硫和
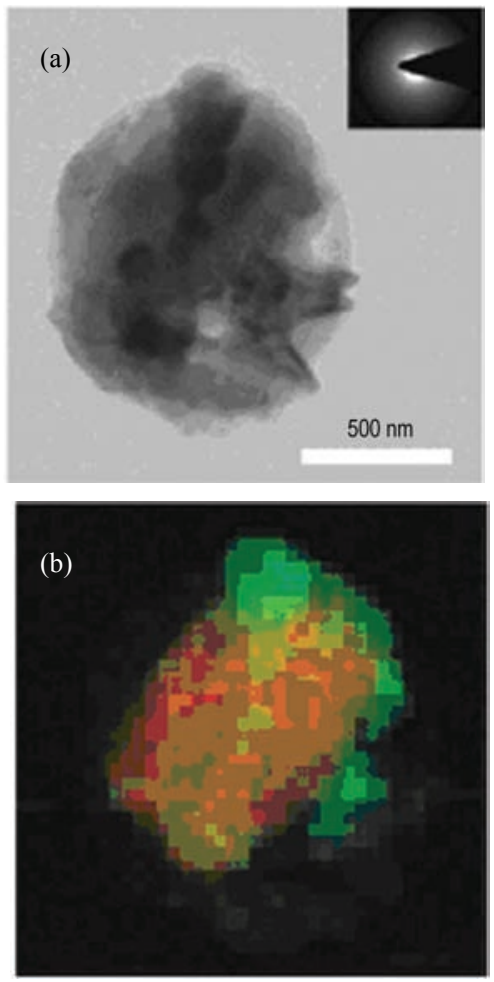

图 $15 \mathrm{Li}_{2} \mathrm{~S} / \mathrm{CMK}-3$ 多孔碳复合材料的 TEM 图(a)和硫碳 元素叠合选定区电子衍射图(b) ${ }^{99}$

Fig.15 (a) TEM image of a single $\mathrm{Li}_{2} \mathrm{~S} / \mathrm{CMK}-3$ mesoporous carbon nanocomposite particle and (b) overlay of carbon and sulfur elemental maps ${ }^{99}$ Fig.(b) shows uniform distribution of lithiated sulfur within the mesoporous carbon matrix.
CMK-3 介孔碳复合得到的硫-碳复合材料并制成薄 膜, 然后再与正丁基锂反应, 得到 $\mathrm{CMK}-3 / \mathrm{Li}_{2} \mathrm{~S}$ 复合 材料. 图 $15 \mathrm{a}$ 显示的是 $\mathrm{Li}_{2} \mathrm{~S} / \mathrm{CMK}-3$ 介孔碳纳米复合 材料的 TEM 图,颗粒大小约为 $0.5-1 \mathrm{~mm}$; 使用 X射 线能量色散谱(EDS)对材料中的碳、硫元素进行分 析结果见图 15b, 图中绿色区域代表介孔碳基体材 料, 而单质硫与此碳材料复合之后由单独显示的红 色演变为图中的桔黄色. 可见, 材料中单质硫均匀地 分布在了介孔碳基体当中

将此材料与金属锂负极组装成半电池, 在 $1 / 8 C$ 的放电倍率下, 其初始放电比容量为 $573 \mathrm{mAh} \cdot \mathrm{g}^{-1}, 5$ 次循环后开始稳定在 $400 \mathrm{mAh} \cdot \mathrm{g}^{-1}$ 左右; 之后与纳 米硅负极材料组装成全电池, 在 $1 C$ 的放电倍率下, 初始比容量为 $423 \mathrm{mAh} \cdot \mathrm{g}^{-1}$ (见图 16), 20 次循环后其 容量维持在 $300 \mathrm{mAh} \cdot \mathrm{g}^{-1}$ 左右; $1 / 8 \mathrm{C}$ 放电倍率下, 初 始容量可达 $482 \mathrm{mAh} \cdot \mathrm{g}^{-1}$, 能量密度为 $630 \mathrm{Wh} \cdot \mathrm{kg}^{-1}$, 高于目前商用的锂离子电池.

Hassoun 等 ${ }^{100}$ 将 $\mathrm{Li}_{2} \mathrm{~S}$ 和 Super P 球磨混合后, 与 粘结剂经过热压处理作为正极材料, 将含 $1 \mathrm{~mol} \cdot \mathrm{L}^{-1}$ $\mathrm{LiPF}_{6}$ 的 $\mathrm{EC} / \mathrm{DMC}($ 体积比 $1: 1$ ) 的电解质浸入 $\mathrm{PEO} /$ 三 氟甲基磺酸锂聚合物基质中, 以此作为凝胶聚合物 电解质(简称为 CGPE). CGPE 聚合物表面膜可作为 物理屏障阻止电解液和电极材料的直接接触, 加上 膜内的饱和多硫化锂溶液, 可以有效降低多硫化锂 在电解液中的溶解, 缓解电池容量衰减. 组成的锂硫 二次电池放电电压可达 $2.5 \mathrm{~V}$, 放电比容量可达 600 $\mathrm{mAh} \cdot \mathrm{g}^{-1}$. 如采用 $\mathrm{Sn} / \mathrm{C}(1: 1)$ 作为负极组成全电池进

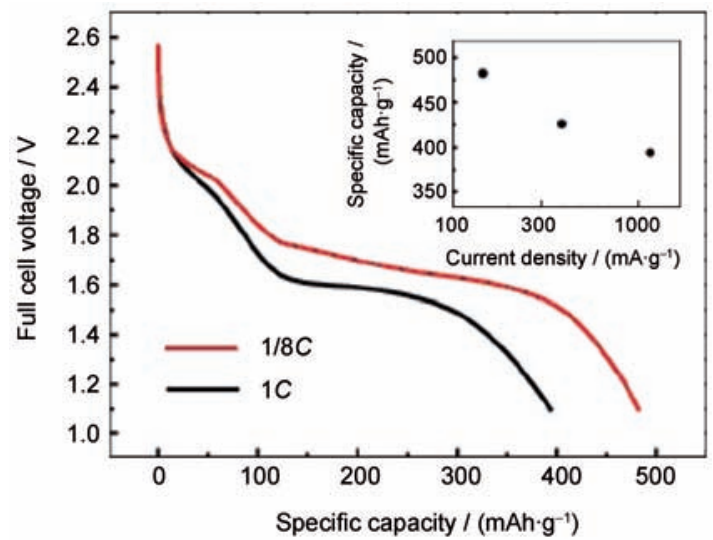

图 $16 \mathrm{Li}_{2} \mathrm{~S} / \mathrm{CMK}-3$ 多孔碳正极与硅纳米线负极组成的全 电池在 $1 C$ 和 $1 / 8 C$ 条件下的首次放电曲线 ${ }^{99}$

Fig.16 First discharge voltage profiles of full battery cells with $\mathrm{Li}_{2} \mathrm{~S} / \mathrm{CMK}-3$ mesoporous carbon nanocomposite cathodes and silicon nanowire anodes at rates of $1 C$ and $1 / 8 C^{99}$ 


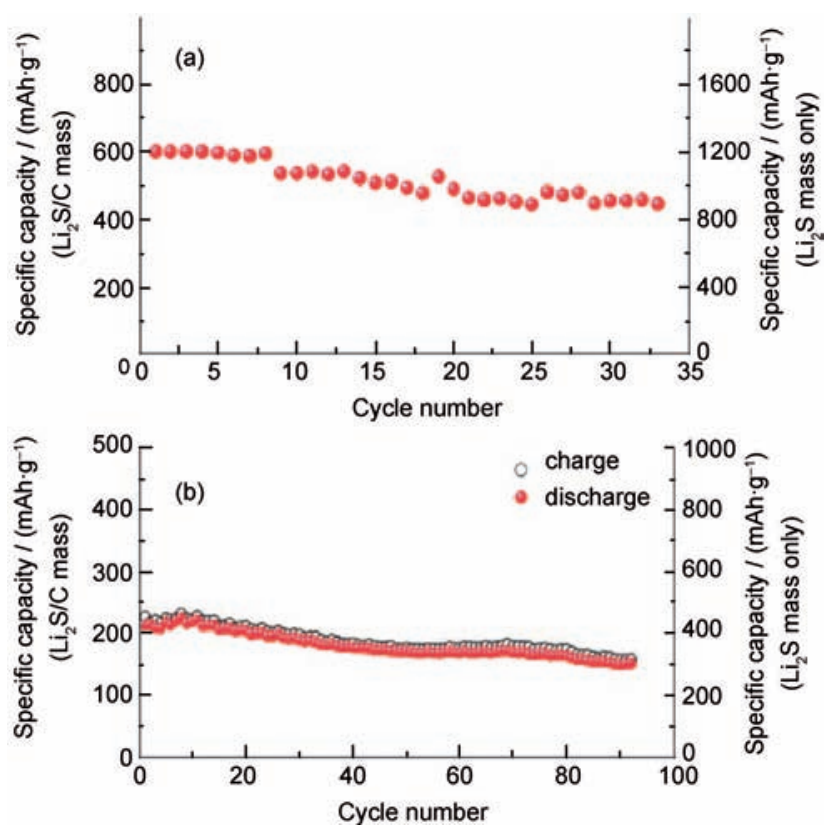

图 $17 \mathrm{Sn} / \mathrm{C} / \mathrm{CPGE} / \mathrm{Li}_{2} \mathrm{~S} / \mathrm{C}$ 电池的循环性能 ${ }^{100}$

Fig.17 Capacity versus cycle number of a Sn/C/CPGE/ $\mathbf{L i}_{2} \mathbf{S} / \mathbf{C}$ battery $^{100}$

(a) $38 \mathrm{~mA} \cdot \mathrm{cm}^{-1} \cdot \mathrm{g}^{-1}(1 / 20 \mathrm{C}), 0.2-4 \mathrm{~V}$ voltage range;

(b) $152 \mathrm{~mA} \cdot \mathrm{cm}^{-1} \cdot \mathrm{g}^{-1}(1 / 5 \mathrm{C}), 0.2-4.6 \mathrm{~V}$ voltage range

行测试, 锡粒子和无定形碳混合在一起可以降低体 积变化, 且锡/碳复合负极具有高度的化学稳定性, 不会与电解液中的多硫化物反应. 电化学测试结果 表明(图 17), 在较低倍率充放电, 电池初始放电比容 量超过 $600 \mathrm{mAh} \cdot \mathrm{g}^{-1}$, 其后容量缓慢衰减. 在较高倍 率充放电, 比容量较低, 即倍率特性较差.

\section{6 结论与展望}

由金属锂作为负极、单质硫或硫基复合材料作 为正极的锂硫二次电池具有非常高的理论能量密 度, 实际能量密度已达到 $300 \mathrm{Wh} \cdot \mathrm{kg}^{-1}$ 以上, 有望进 一步提高到 500-600 Wh $\cdot \mathrm{kg}^{-1}$, 为目前商业化的锂 离子电池的 4 倍左右, 并且具有绿色环保和低成本 等显著优势, 从而成为目前高能二次电池研究的热 点之一, 存在的关键问题在于锂硫电池循环性能差, 不能满足实际应用需要.

单质硫作为正极材料虽然比容量高, 但导电性 及循环稳定性较差; 有机硫化物作为一种高比容量 的储能材料, 可以通过设计材料的分子结构来提高 其电化学活性; 采用 $\mathrm{Li}_{2} \mathrm{~S}$ 作为正极材料, 使得电池采 用非锂负极成为可能, 实际检测的电池比容量也高 于现在的商用锂电池, 但循环性能相对较差, 并且弱 化了锂硫二次电池高能量密度的优势. 相比之下, 硫
基复合材料成为了目前锂硫二次电池正极材料研究 的主流, 如多孔-介孔碳/硫、聚合物/硫复合材料, 基 本思想是将单质硫以纳米尺寸与基体材料复合或化 合, 以稳定材料结构、提高其电化学性能. 可以预见 硫基复合材料仍然会是今后锂硫二次电池正极方面 深入研究的重点, 策略在于使单质硫在纳米尺寸甚 至分子水平与导电基体充分复合, 在保证硫基复合 材料高电化学活性和循环稳定性的同时, 尽可能提 高复合材料中活性物质硫的含量, 从而获得具有高 能量密度和长循环寿命的硫基复合材料. 再配以具 有长循环寿命的金属锂作为负极, 以及功能电解质 体系, 最终组装成的锂硫二次电池可作为高性能动 力电池和储能电池广泛地应用在新能源领域.

\section{References}

(1) Tarascon, J. M.; Armand, M. Nature 2001, 414, 359.

(2) Winter, M.; Brodd, R. Chem. Rev. 2004, 104, 4245.

(3) Whittingham, M. S. Chem Rev. 2004, 104, 4271.

(4) Winter, M.; Besenhard, J. O.; Spahr, M. E.; Novak, P. $A d v$. Mater. 1998, 10, 725.

(5) Padhi, A. K.; Najundaswamy, K. S.; Goodenough, J. B. J. Electrochem. Soc. 1997, 144, 1188.

(6) Chung, S. Y.; Bloking, J. T.; Chiang, Y. M. Nat. Mater. 2002, 1, 123.

(7) Kang, B.; Ceder, G. Nature 2009, 458, 190.

(8) Marmorstein, D.; Yu, T. H.; Striebel, K. A.; McLarnon, F. R.; Hou, J.; Cairns, E. J. J. Power Sources 2000, 89, 219.

(9) Dejonghe, L. C.; Mayying, C.; Katz, B. D.; Visco, S. J. High Capacity/High Discharge Rate Rechargeable Positive Electrode. US Patent 6200704, 2001-03-13.

(10) Xu, Z. S.; Terjea, S.; Yordanm, G. Electrochemical Cells with High Volumetric Density of Electroactive Sulfur-containing Materials in Cathode Active Layers. US Patent 6302928, 2001-10-16.

(11) Siemens Company. Mobile Communications-power, Pictures of the future/Spring 2002; pp15.

(12) Klauk, H.; Zschieschang, U.; Pflaum, J.; Halik, M. Nature 2007, 445,745 .

(13) Kumaresan, K.; Mikhaylik, Y.; White, R. E. J. Electrochem. Soc. 2008, 155, A576.

(14) Li, Y. J.; Zhan, H.; Liu, S. Q.; Huang, K. L.; Zhou, Y. H. J. Power Sources 2010, 195, 2945.

(15) Yuriy, V. M.; James, R. A. J. Electrochem. Soc. 2004, 151, A1969.

(16) Grigorevna, M. A.; Trofimov, B.; Kovalev, I. P.; Skotheim, T. A. Electroactive High Storage Capacity Polyacetylene-co-polysulfur Materials and Electrolytic Cells Containing Same. US Patent 6117590, 2000-09-12.

(17) Chu, M. Y.; DeJonghe, L. C.; Visco, S. J.; Katz, B. D. Liquid 
Electrolyte Lithium-sulfur Batteries. WO Patent 9919931, 1999-04-22.

(18) Jung, Y. J.; Kim, S. Electrochem. Commun. 2007, 9, 249.

(19) Cheon, S. E.; Ko, K. S.; Cho, J. H.; Kim, S. W.; Chin, E. Y.; Kim, H. T. J. Electrochem. Soc. 2003, 150, A796.

(20) Cheon, S. E.; Ko, K. S.; Cho, J. H.; Kim, S. W.; Chin, E. Y. Kim, H. T. J. Electrochem. Soc. 2003, 150, A800.

(21) Cheon, S. E.; Cho, J. H.; Ko, K. S.; Kwon, C. W.; Chang, D. R.; Kim, H. T.; Kim, S. W. J. Electrochem. Soc. 2002, 149, A1437.

(22) Choi, Y. J.; Kim, K. W.; Ahn, H. J.; Ahn, J. H. J. Alloy. Compd. 2008, 449, 313.

(23) Kim, N. I.; Lee, C. B.; Seo, J. M.; Lee, W. J.; Roh, Y. B. J. Power Sources 2004, 132, 209.

(24) Sun, J.; Huang, Y. Q.; Wang, W. K.; Yu, Z. B.; Wang, A. B.; Yuan, K. G. Electrochim. Acta 2008, 53, 7084.

(25) Sun, J.; Huang, Y. Q.; Wang, W. K.; Yu, Z. B.; Wang, A. B.; Yuan, K. G. Electrochem. Commun. 2008, 10, 930.

(26) Zhang, W. Y.; Huang, Y. Q.; Wang, W. K.; Huang, C. J.; Wang, Y.; Yu, Z. B.; Zhang, H. J. Electrochem. Soc. 2010, 157, A443.

(27) Peled, E.; Sternberg, Y.; Gorenshetein, A.; Lavi, Y. J. Electrochem. Soc. 1989, 136, 1621.

(28) Yu, Z. B.; Wang, W. K.; Wang, A. B.; Yuan, K. G.; Yang, Y. S. Battery Bimonthly 2006, 36, 3. [余仲宝, 王维坤, 王安邦, 苑克 国, 杨裕生. 电 池, 2006, 36, 3.]

(29) Wen, Z. Y.; Itoch, T.; Ichikaw, Y.; Kubo, M.; Yamano, O. Solid State Ionics 2000, 135, 47.

(30) Jeong, S. S.; Lim, Y. T.; Choi, Y. J.; Cho, G. B.; Kim, K. W.; Ahn, H. J.; Cho, K. K. J. Power Sources 2007, 174, 745.

(31) Shin, J. H.; Kim, K. W.; Ahn, H. J.; Ahn, J. H. Mater. Sci. Eng. B 2002, 95, 148.

(32) Ryu, H. S.; Ahn, H. J.; Kim, K. W.; Ahn, J. H.; Lee, J. Y. J. Power Sources 2006, 153, 360.

(33) Ma, P.; Xu, Y. H.; Zhang, B. H.; Yin, J. L.; Meng, X. L. Battery Bimontyly 2006, 36, 426. [马 萍, 徐宇虹, 张宝宏, 殷金玲, 孟祥利. 电 池, 2006, 36, 426.]

(34) Yuan, L. X.; Feng, J. K.; Ai, X. P.; Cao, Y. L.; Chen, S. L.; Yang, H. X. Electrochem. Commun. 2006, 8, 610.

(35) Wang, J.; Chew, S. Y.; Zhao, Z. W.; Ashraf, S.; Wexler, D.; Ng, S. H.; Chou, S. L.; Liu, H. K. Carbon 2008, 46, 229.

(36) Hayashi, A.; Ohtomo, T.; Mizuno, F.; Tadanaga, K.; Tatsumisago, M. Electrochem. Commun. 2003, 5, 701.

(37) Novak, P. Chem. Rev. 1997, 97, 207.

(38) Naoi, K.; Kawase, K.; Inoue, Y. J. Electrochem. Soc. 1997, 144, L170.

(39) Xu, G. X. The Application Research of Polymer Electrode with High Capacity Used in Secondary Lithium Batteries. Ph. D. Dissertation, Tianjin University, Tianjin, 2004. [徐国祥. 大容 量聚合物电极材料在二次锂电池中的应用研究[D]. 天津: 天津大学, 2004.]

(40) Ning, Y. N.; Wang, W. K.; Huang, Y. Q.; Wang, A. B.; Cao, G. P.; Huang, M. Z. Chem. Ind. Eng. Progr. 2004, 23, 650. [宁雅 楠, 王维坤, 黄雅钦, 王安邦, 曹高萍, 黄明智. 化工进展, 2004, 23, 650.]
(41) Yang, Y. S.; Wang, W. K.; Yuan, K. G.; Cao, G. P.; Wang, A. B. Battery Bimonthly 2002, 32, S1. [杨裕生, 王维坤, 苑克国, 曹高萍, 王安邦. 电池, 2002, 32, S1.]

(42) Li, J. L.; Zhan, H.; Zhou, L.; Deng, S. R.; Li, Z. Y.; Zhou, Y. H. Electrochem. Commun. 2004, 6, 515.

(43) Skotheim, T. A; Kovalev, I. P. A. Method of Making Electroactive High Storage Capacity Polycarbon-sulfide Materials and Electrolytic Cells Containing same. US Patent 5690702, 1997-11-25.

(44) Skotheim, T. A.; Kovalev, I. P. Electroactive High Storage Capacity Polycarbon-sulfide Materials and Electrolytic Cells Containing Same. US Patent 5601947, 1997-02-11.

(45) Skotheim, T. A.; Trofimov, B.; Grigorevna, M. A.; Kovalev, I. P. Electroactive High Storage Capacity Polyacetylene-co-polysulfur Materials and Electrolytic Cells Containing Same. US Patent 5529860, 1996-06-25.

(46) Skotheim, T. A.; Trofimov, B.; Grigorevna, M. A.; Kovalev, I. P. Electroactive high storage capacity polyacetylene-co-polysulfur materials and electrolytic cells containing same. US Patent 6117590, 2000-09-12.

(47) Shouji, E.; Matsui, H.; Oyama, N. J. Electroanal. Chem. 1996, 417, 17.

(48) Kim, D.; Jensen, H.; Benassi, R.; Taddei, F.; Antonello, S.; Gennaro, A.; Maran, F. J. Am. Chem. Soc. 1999, 121, 1750.

(49) Oyama, N.; Tatsume, T.; Sato, T.; Soromura, T. Nature 1995, 373, 598.

(50) Matsumoto, F.; Ozaki, M.; Inatomi, Y.; Paulson, S. C.; Oyama, N. Langmuir 1999, 15, 857.

(51) Sotomura, T.; Tatsuma, T.; Oyama, N. J. Electrochem. Soc. 1996, 143, 3152 .

(52) Oyama, N.; Pope, J. M.; Sotomura, T. J. Electrochem. Soc. 1997, 144, L47.

(53) Yu, L.; Wang, X. H.; Li, J.; Jing, X. B.; Wang, F. S. J. Electrochem. Soc. 1999, 146, 1712.

(54) Yu, L.; Wang, X. H.; Jing, X. B.; Wang, F. S. J. Power Sources 1998, 73, 261.

(55) Park, J. E.; Park, S. G.; Koukitu, A.; Hatozaki, O.; Oyama, N. J. Electrochem. Soc. 2003, 150, A959.

(56) Xue, L. J.; Li, J. X.; Hu, S. Q.; Zhang, M. X; Zhou, Y. H.; Zhan, C. M. Electrochem. Commun. 2003, 5, 903.

(57) Li, Y. J.; Zhan, H.; Kong, L. B.; Zhan, C. M.; Zhou, Y. H. Electrochem. Commun. 2007, 9, 1217.

(58) Han, X. Y.; Chang, C. X.; Yuan, L. J.; Sun, T. L.; Sun, J. T. $A d v$. Mater. 2007, 19, 1616.

(59) Cheon, S. E.; Choi, S. S.; Han, J. S.; Choi, Y. S.; Jung, B. H.; Lin, H. S. J. Electrochem. Soc. 2004, 151, A2067.

(60) Wang, J. L.; Yang, J.; Xie, J.Y.; Xu, N. X.; Li, Y. Electrochem. Commun. 2002, 4, 499.

(61) Wang, J. L.; Liu, L.; Ling, Z. J.; Yang, J.; Wan, C. R.; Jiang, C. Y. Electrochim. Acta 2003, 48, 1861.

(62) Han, S. C.; Song, M. S.; Lee, H.; Kim, H. S.; Ahn, H. J.; Lee, T. Y. J. Electrochem. Soc. 2003, 150, A889.

(63) Zheng, W.; Hu, X. G.; Zhang, C. F. Rare Metal Mat. Eng. 2006, 
35, 1223. [郑 伟, 胡信国, 张翠芬. 稀有金属材料与工程, 2006, 35, 1223.]

(64) Zheng, W. Preparation and Electrochemical Performance of Elemental Sulfur Composite Cathode Materials for Rechargeable Lithium Batteries. Ph. D. Dissertation, Harbin Institute of Technology, Harbin, 2006. [郑 伟. 二次锂电池单质硫复合 正极材料的制备及电化学性能研究 [D]. 哈尔滨: 哈尔滨工业 大学, 2006.]

(65) Li, D. D. Study on the Materials Used in Lithium/Sulfur Secondary Batteries. M. S. Dissertation, Shanghai Jiao Tong University, Shanghai, 2008. [李丹丹. 二次锂电池单质硫复合 正极材料的制备及电化学性能研究[D]. 上海: 上海交通大学, 2008.]

(66) Zheng, W.; Liu, Y. W.; Hu, X. G.; Zhang, C. F. Electrochim. Acta 2006, 51, 1330.

(67) Zhang, B.; Lai, C.; Zhou, Z.; Gao, X. P. Electrochim. Acta 2009, 54, 3708 .

(68) Lai, C.; Gao, X. P.; Zhang, B.; Yan, T. Y.; Zhou, Z. J. Phys. Chem. C 2009, 113, 4712

(69) Ji, X.; Kyu, T. L.; Nazar, L. F. Nat. Mater. 2009, 8, 500.

(70) Kim, H.; Cho, J. Nano Lett. 2008, 8, 3688.

(71) Liang, C. D.; Dudney, N. J.; Howe, J. Y. Chem. Mater. 2009, 21 , 4724 .

(72) Zhu, X. J.; Wen, Z. Y.; Gu, Z. H.; Lin, Z. X. J. Power Sources 2005, 139, 269.

(73) Wang, J. L.; Yang, J.; Xie, J. Y.; Xu, N. X. Adv. Mater. 2002, 14, 963.

(74) Wang, J. L.; Yang, J.; Wan, C. R.; Du, K.; Xie, J. Y.; Xu, N. X. Adv. Func. Mater. 2003, 13, 487.

(75) Wang, J. L.; Xie, J. Y.; Yang, J.; Xu, N. X.; Liu, L. Elemental Sulfur/Conductive Polymer Composite Cathode Material for Electrochemical Power Sources and the Method for Forming the Same. CN Patent 02111403.X, 2005-08-10. [王久林, 解晶荣, 杨 军, 徐乃欣, 刘 路. 电化学电源正极用单质硫/导电聚合 物复合材料及其制备方法: 中国, ZL 02111403.X[P]. 2005-08-10.]

(76) Wang, J. L. Preparation and Electrochemical Performances of Sulfur Based Cathode Materials for Rechargeable Lithium Batteries. Ph. D. Dissertation, Shanghai Institute of Microsystem and Information Technology, Shanghai, 2002. [王久林. 二次锂 电池用含硫正极材料的制备及电化学性能研究[D]. 上海: 上 海微系统与信息技术研究所, 2002.]

(77) Yu, X. G.; Xie, J. Y.; Yang, J.; Huang, H. J.; Wang, K.; Wen, Z. S. J. Electroanal. Chem. 2004, 573, 121.

(78) Li, Y.; Fu, X.; Hu, G. X.; Xie, X. H.; Xie, J. Y. Chin. J. Power Sources 2004, 28, 261.

(79) Li, Y. A Novel S-containing Composite Material for the Cathodes of Rechargeable Lithium Batteries. M. Sc. Dissertation, Shanghai Institute of Microsystem and Information Technology, Shanghai, 2003. [ 李 颖. 新型锂二次电池正极含硫复合材料的研 究 [D]. 上海: 上海微系统与信息技术研究所, 2003.]

(80) Yu, X. G.; Xie, J. Y.; Li, Y.; Huang, H. J.; Lai, C. Y.; Wang, K.
J. Power Sources 2005, 146, 335.

(81) Yu, X. G. Structure, Performance and Lithium Storage Mechanism of Conductive Sulfur-containing Polymers. Ph. D. Dissertation, Shanghai Institute of Microsystem and Information Technology, Shanghai, 2005. [喻献国. 导电含硫 聚合物的结构与性能及储锂机理研究 $[D]$. 上海: 上海微系统 与信息技术研究所, 2005.]

(82) Yu, X. G.; Xie, J. Y.; Huang, H. J.; Wang, K. Chin. J. Nonferrous Metal. Soc. 2004, 14S3, 355. [喻献国, 解晶莹, 黄海江, 王 可. 中国有色金属学报, 2004, 14S3, 355.]

(83) Yuriy, V. M.; James, R. A. J. Electrochem. Soc. 2003, 150, A306.

(84) Wang, J. L.; Wang, Y. W.; He, X. M.; Ren, J. G.; Jiang, C. Y.; Wan, C. R. J. Power Sources 2004, 138, 271.

(85) He, X. M.; Pu, W. H.; Ren, J. G.; Wang, L.; Wang, J. L.; Jiang, C. Y.; Wan, C. R. Electrochim. Acta 2007, 52, 7372.

(86) Pu, W. H.; He, X. M.; Wang, L.; Jiang, C. Y.; Wan, C. R. Ionics 2007, 13, 273.

(87) Li, W. L.; Pu, W. H.; He, X. M.; Ren, J. G.; Wang, L.; Jiang, C. Y.; Wan, C. R. New Chem. Mater. 2008, 36, 28. [黎文路, 蒲薇华, 何向明, 任建国, 王 莉, 姜长印, 万春荣. 化工新型 材料, 2008, 36, 28.]

(88) Wu, Y. L.; Yang, J.; Wang, J. L.; Yin, L. C; Nuli, Y. N. Acta Phys. -Chim. Sin., 2010, 26, 283. [伍英蕾, 杨 军, 王久林, 尹利超, 努丽燕娜. 物理化学学报, 2010, 26, 283.]

(89) Wu, Y. L. Study of Sulfur-based Composite Cathodes for Secondary Lithium-sulfur Battery. M. S. Dissertation, Shanghai Jiao Tong University, Shanghai, 2009. [伍英蕾. 锂-硫二次电 池硫基复合正极的研究 [D]. 上海: 上海交通大学, 2009.]

(90) Wei, W.; Wang, J. L.; Zhou, L. J.; Yang, J.; Schumann, B.; Nuli, Y. N. Electrochem. Commun. 2011, doi:10.1016/ j.elecom.2011.02.001.

(91) Yin, L. C.; Wang, J. L.; Yang, J.; Nuli, Y. N. J. Mater. Chem. 2011, accepted

(92) Wang, J. L.; Wei, W.; Yang, J.; Zhou, L. J. Cathode Material for Li-S Battery and Method for Forming the Same. PCT/CN Pat. Appl. 2010/077530, 2010.

(93) Qiu, L. L.; Zhang, S. C.; Zhang, L.; Sun, M. M.; Wang, W. K. Electrochim. Acta 2010, 55, 4632.

(94) Sun, M. M.; Zhang, S. C.; Jiang, T.; Zhang, L.; Yu, J. H. Electrochem. Commun. 2008, 10, 1819.

(95) Wu, F.; Wu, S. X.; Chen, R. J.; Chen, J. Z.; Chen, S. Electrochem. Solid State Lett. 2010, 13, A29.

(96) Sun, H.; He, X. M.; Ren, J. G.; Li, J. J.; Jiang, C. Y.; Wan, C. R. Electrochim. Acta 2007, 52, 4312.

(97) Zhou, Y. N.; Wu, C. L.; Zhang, H.; Wu, X. J.; Fu, Z. W. Electrochim. Acta 2007, 52, 3130.

(98) Takeuchi, T.; Sakaebe, H.; Kageyama, H.; Senoh, H.; Sakai, T.; Tatsumi, K. J. Power Sources 2010, 195, 2928.

(99) Yang, Y.; McDowell, M. T.; Jackson, A.; Cha, J. J.; Hong, S. S.; Cui, Y. Nano Lett. 2010, 10, 1486.

(100) Hassoun, J.; Scrosati, B. Angew. Chem. Int. Edit. 2010, 49, 2371. 